\title{
Consumer resistance against regulation: the case of health care
}

\author{
Peter Zweifel · Harry Telser · Stephan Vaterlaus
}

(C) 2006 Springer Science+Business Media, Inc.

\begin{abstract}
Regulation fostering Managed Care alternatives in health insurance is spreading. This work reports on an experiment designed to measure the amounts of compensation asked by the Swiss population (in terms of reduced premiums) for Managed-Care type restrictions in the provision of health care. It finds that restrictions on the freedom of physician choice would require an average compensation of more than one-third of the premium, while generic substitution even meets with a small willingness to pay. Marked preference heterogeneity is an argument against regulation imposing uniformity of contract in Swiss social health insurance.
\end{abstract}

Keywords Health insurance - Health care - Regulation - Preference measurement . Discrete choice experiments

JEL Classification $\mathrm{L} 51 \cdot \mathrm{D} 61 \cdot \mathrm{C} 93 \cdot \mathrm{I} 11 \cdot \mathrm{I} 18$

\section{Introduction}

Health care expenditure has been soaring in all industrialized countries. The policy response has been of two types (Cutler, 2002). Either outright rationing (hidden or open) was imposed, or health insurers were mandated to introduce policies with more stringent provisions (higher deductibles, higher rates of coinsurance, or so-called Managed Care options such as HMOs). The United States has taken the latter route, resulting in more than two-third of the insured population being covered by some Managed Care alternative (Interstudy, 2003). Other countries are considering the possibility of actually forcing consumers into Managed-Care

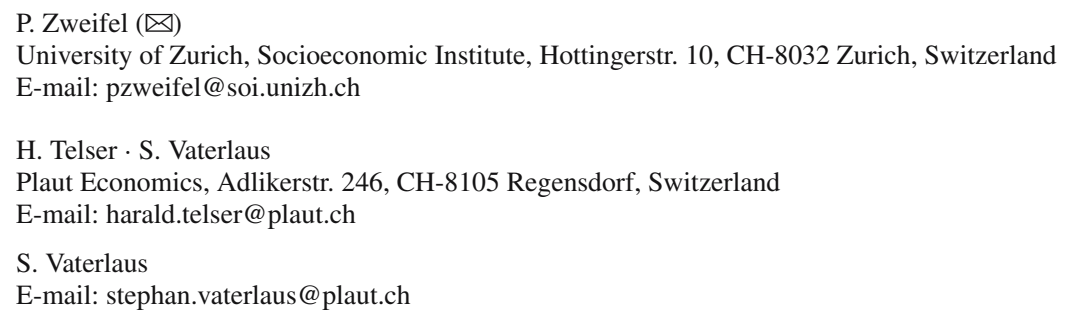


type contracts. The common motive for these policies is that governments, who share (e.g. through subsidization of hospitals) part of the burden of increasing health care expenditure, seek ways to alleviate this burden. The pro-choice approach seeks to motivate individuals to engage in self-rationing through the choice of appropriate contracts. However, the experience of the United States shows that restrictions particularly on free choice of physician are not accepted easily; in fact, consumers strongly turned against Health Maintenance Organizations, the most restrictive variant of Managed Care ("HMO backlash"; see e.g. The Economist, 28 June 2001).

Such resistance indicates that more stringent restrictions on the use of healthcare services are viewed as regulations, although they go along with lower premiums if imposed by (competitive) health insurers. Apparently, however, these premium reductions are not sufficient to compensate the insured for their loss of expected utility. This argument prompts a very simple question, viz. what is the amount of compensation necessary to overcome consumer resistance against more stringent regulation of health care?

The objective of this paper is to present evidence on the likely magnitude of compensation required in a country whose citizens are accustomed to a great deal of choice in health care, similar to the United States. It reports on experiments involving the Swiss resident population that are designed to measure resistance against Managed-Care type restrictions in financial terms. The tool used is Discrete Choice Experiments (DCE), a novel approach to preference and willingness-to-pay measurement that is rapidly gaining acceptance. There are three main findings of this study: (1) Giving up free choice of physician requires one-third of the present average insurance premium to be voluntarily accepted, a high but limited amount, contradicting traditional ideology of the Swiss (and other) medical associations claiming free choice of physician to be priceless; (2) The combination of restrictions typically imposed by Managed Care requires superadditive compensation, much as predicted by microeconomic theory; (3) There is strong evidence of preference heterogeneity, suggesting that uniform regulation of the provision of health care may impose a substantial efficiency loss on the population of even a small country such as Switzerland with its $7.2 \mathrm{mn}$. inhabitants.

The plan of this paper is as follows. In the second section, DCE are introduced as a tool for preference measurement. A short literature review concerning the merits of DCE compared to the conventional contingent valuation $(\mathrm{CV})$ alternative will be given, followed by some theoretical background for econometric specification. The third section informs about the design of the present experiment. The attributes of health care provision that are relevant to consumers must be identified and levels found that while not deemed unrealistic induce respondents to switch between the status quo and the alternatives proposed. Otherwise, nothing can be learned about their preferences. A description of the sample is also given. The fourth section contains the econometric estimates. The starting point is a basic model that links respondents' change in utility simply to the differences in attributes between the status quo and the proposed alternatives without admitting any systematic heterogeneity in terms of marginal utilities of income. In a second step, socio-economic influences enter the picture, providing evidence of marked heterogeneity of preferences not only between language regions but also age and income groups. The final section presents conclusions and suggestions for future work.

\section{DCE as a tool for preference measurement}

\subsection{Literature review}

The method of choice for evaluating goods that are either public or not yet on the market is cost-benefit-analysis. Rather than relying on the human capital approach (which is not 
compatible with standard microeconomics (see e.g. Zweifel \& Breyer, 1997, ch. 2), researchers increasingly determine the utility side of the equation using willingness-to-pay (WTP) estimates. Sometimes it is possible to infer these preferences from individual behavior on the market. However, often recourse must be had to actually asking individuals about their WTP. Here, the traditional approach, pioneered in environmental economics and transportation economics, has been CV (see e.g. the survey by Mitchell \& Carson, 1989). The problem with $\mathrm{CV}$ is that usually all attributes of the alternative in question are kept constant, except price, which is rather artificial since in real life situations, available alternatives almost always differ from the status quo in several attributes. This artificiality of CV has several unwanted consequences (see Mitchell \& Carson, 1989, ch. 11 for an overview). First, respondents seem to have the tendency to answer with yes when responding to discrete CV questions in order to express their motivations instead of giving their true preferences (yea-saying). Second, compliant and strategic behaviors may lead respondents to inaccurately represent their preferences, because there are no incentives to tell the truth when the constructed market is too hypothetical.

These disadvantages are avoided by an approach that originates from so-called conjoint analysis in marketing in the 1970s (Cattin and Wittink, 1982; Gustafson, Herrmann \& Huber, 2000). Since all attributes (including price) are varied simultaneously in the course of the experiment, marginal rates of substitution between all attributes (given the appropriate experimental design) can be derived from responses. Compared to other variants, such as rating and ranking, DCE (which require respondents to merely indicate "accept" or "reject", relative to the status quo) have the advantage of being firmly rooted in decision theory. In health economics, DCE have been applied starting in 1990s (Ryan \& Hughes, 1997; Johnson \& Desvousges, 1997; Telser \& Zweifel, 2002). While the approach has been used for measuring WTP for specific products and procedures, the idea of defining an entire health care system as such a product is more recent. The first instance may well be Gyrd-Hansen and Slothuus (2002), who measured the preferences of the Danish population for a change from present tax-based financing to an alternative that would involve increased out-of-pocket payments. To our knowledge, however, no attempt has been made to date to measure the resistance of consumers against regulation in health care using the DCE approach.

\subsection{Theoretical background}

Following Lancaster (1966), the basic assumption is that consumers derive utility from the attributes they enjoy through the use of goods rather than from the quantity of goods per se. Therefore, the utility of consumer $i$ who exclusively consumes good $j$ can be written as

$$
U_{i j}=u\left(x_{j}, b_{j}, z, s_{i}, \varepsilon_{i j}\right)
$$

Here, $U$ denotes the utility, whose value is determined by a function that is identical for all individuals $i, x_{j}$ the quantity of good $x$ in alternative $j, b_{j}$ the associated vector of attributes, $z$ the numéraire good, and $s_{i}$ socioeconomic characteristics of individual $i$. Finally, $\varepsilon_{i j}$ is a random variable that reflects the fact that while decisions may be deterministic, their determinants cannot be fully observed by the experimenter, which imparts a stochastic element to decision making. This specification amounts to the random utility model (McFadden, 1974). Due to utility maximization, the indirect utility function $v_{i j}$ can be written as

$$
V_{i j}=v\left(p_{j}, b_{j}, y_{i}, s_{i}, \varepsilon_{i j}\right) \equiv u\left(x_{j}\left(p_{j}, b_{j}, y_{i}, s_{i}, \varepsilon_{i j}\right), b_{j}, z\left(p_{j}, b_{j}, y_{i}, s_{i}, \varepsilon_{i j}\right), s_{i}, \varepsilon_{i j}\right)
$$




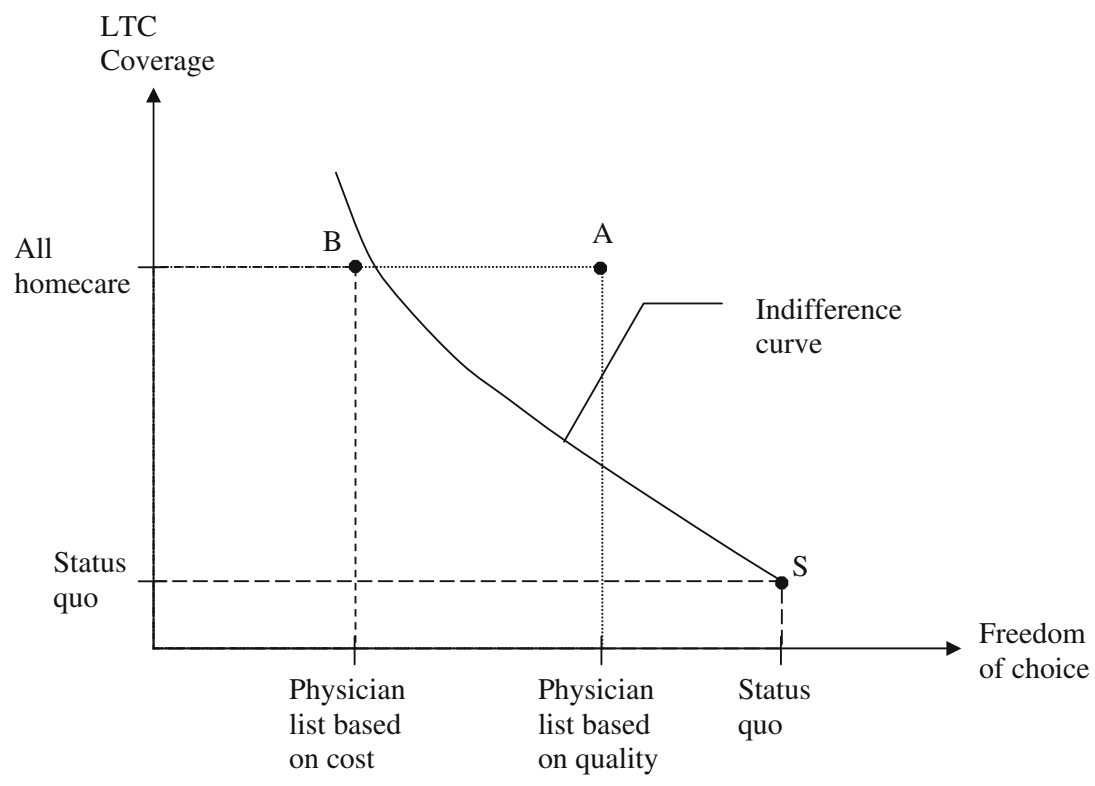

Fig. 1 Freedom of choice and coverage of long-term care (LTC) as attributes

with $p_{j}$ denoting the price for alternative $j$ and $y_{i}$ the income of individual $i$. Focusing on the deterministic component of Equation (2), Fig. 1 can be used to illustrate the derivation of WTP from a series of discrete choices (i.e. yes-or-no). Two of the attributes in the present context (to be described in Section 3.1 below) are freedom of choice and insurance coverage of long-term care (LTC) expenditure. The status quo in Switzerland, symbolized by point $S$, is characterized by an essentially unconstrained choice of physician, combined with very limited LTC coverage. In the course of the experiment, let there be an alternative $A$ that restricts choice to physicians selected by the health insurer on the basis of their quality of treatment, while LTC coverage is extended to include all home care. If the respondent opts in favor of alternative $A$ rather than the status quo, his or her indifference curve must run below point $A$. Next, the respondent is asked to weigh alternative $B$, where the extension of LTC coverage goes along with a much more severe restriction of physician choice (viz. a selection of physicians based on cost considerations only). If the same respondent expresses preference in favor of the status quo this time, his or her indifference curve must run above point $B$. By repeating the experiment, it becomes possible to approximately construct respondents' indifference curve and with it, the marginal rate of substitution between the two attributes considered. This means that

$$
\operatorname{MRS}=\frac{\partial v\left(p_{j}, b_{j}, y_{i}, s_{i}, \varepsilon_{i j}\right) / \partial b_{k}}{\partial v\left(p_{j}, b_{j}, y_{i}, s_{i}, \varepsilon_{i j}\right) / \partial b_{m}}
$$

can be inferred from the choice behavior of participants in a DCE. In addition, if attribute $m$ is the premium reduction (and hence increase in income) associated with a restriction of freedom of choice, the MRS is nothing but the marginal willingness-to-pay (WTP) for avoiding this restriction, or the other way around, the marginal compensation asked for accepting a regulation that limits freedom of choice in the event of illness. 
Conclusion 1: For non-marketed goods such as Managed-Care type health insurance policies, discrete choice experiments permit to interpolate indifference curves in attribute space and hence to determine relevant marginal rates of substitution.

\subsection{Stochastic specification}

The usual assumption now is that indirect utility $v_{j}$ can be split up in a systematic and a stochastic component (Ben-Akiva \& Lerman, 1983, ch. 3),

$$
v\left(p_{j}, b_{j}, y_{i}, s_{i}, \varepsilon_{i j}\right)=w\left(p_{j}, b_{j}, y_{i}, s_{i}\right)+\varepsilon_{i j}
$$

Now consumer $i$ will decide in favor of alternative $j$ if the utility associated with $j$ exceeds the value associated with the status quo. Therefore, if $P_{i j}$ denotes the probability of choosing alternative $j$, one has

$$
\begin{aligned}
P_{i j} & =\operatorname{Prob}\left[w\left(p_{j}, b_{j}, y_{i}, s_{i}\right)+\varepsilon_{i j} \geq w\left(p_{l}, b_{l}, y_{i}, s_{i}\right)+\varepsilon_{i l}, \forall l \neq j\right] \\
& =\operatorname{Prob}\left[\varepsilon_{i l}-\varepsilon_{i j} \leq w\left(p_{j}, b_{j}, y_{i}, s_{i}\right)-w\left(p_{l}, b_{l}, y_{i}, s_{i}\right), \forall l \neq j\right]
\end{aligned}
$$

For alternative $j$ to be chosen, the systematic utility difference therefore must exceed the purely chance-driven difference. Implementation of this criterion requires the specification of a joint density function for the stochastic term, defined over the set of scenarios. The multivariate normal distribution (Probit) has the advantage over extreme value distributions that in the multivariate case, the assumption of independence of irrelevant alternatives need not be imposed. Therefore, the (computationally more demanding) less restrictive Probit alternative is used in the following. In addition, a linear approximation of the systematic part of the utility function has been shown to usually be of sufficient precision in several empirical studies (Louviere, Hensher \& Swait 2000, ch. 4). In the present context, generalizing the specification to include quadratic terms did not result in an improved statistical fit. The point of departure therefore will be an indirect utility function that is linear in the retained product attributes,

$$
v_{j}=\beta_{0}+\sum_{k=1}^{K} \beta_{k} b_{j k}+\beta_{p} p_{j}+\varepsilon_{i j}, \quad \text { with } \varepsilon_{i j}=\eta_{i}+v_{i j},
$$

where the $\beta$ are parameters to be estimated, the $b_{j k}$ the attributes $(k=1, \ldots, K)$ except the insurance premium proposed in scenario $j, p_{j}$ the price attribute (i.e. the premium), and $\varepsilon_{i j}$ an error term consisting of an individual-specific component $\eta_{i}$ that is the same across scenarios and $v_{i j}$ a component that varies across scenarios (random-effects specification).

When the change of the attribute is non-marginal, WTP for the change can be approximated by the product of marginal WTP (MWTP) times the change in the attribute from level $k^{0}$ to $k^{*}$ as follows (Hanemann, 1983),

$$
W T P\left[b_{k}^{*}-b_{k}^{0}\right]=\left(b_{k}^{*}-b_{k}^{0}\right) \cdot M W T P_{k}=\left(b_{k}^{*}-b_{k}^{0}\right) \cdot \frac{\left(\partial v / \partial b_{k}\right)}{-(\partial v / \partial p)}
$$

If the WTP for the modification of several (or all) attributes has to be calculated, these WTP values are simply summed over all $K$ attributes (Johnson \& Desvousges, 1997),

$$
W T P\left[b_{k}^{*}-b_{k}^{0}\right]=\frac{\sum_{k=1}^{K}\left[\left(b_{k}^{*}-b_{k}^{0}\right) \cdot\left(\partial v / \partial b_{k}\right)\right]}{-(\partial v / \partial p)}
$$

From Equation (3), one knows that the negative value of the coefficient pertaining to the price attribute $\left(-\beta_{p}\right)$ is the marginal utility of income. In a more comprehensive estimation 
including socioeconomic characteristics, marginal utilities vary with those characteristics, implying that marginal and total WTP values can only be calculated conditional on the values of these other explanatory variables.

\section{Description of the experiment}

For the DCE, the following attributes were retained after extensive consultations with health insurance and medical experts. A crucial characteristic of Managed-Care plans is restricted physician choice. The most stringent alternative is for the health insurer to select providers using but cost criteria by limiting its list to those who do not exceed the average of cost per case by a certain multiple (PHYSCOST $=1$, status quo $=0$ ). Another, less harsh variant is to use quality criteria such as specialty training completed and continued education effort (PHYSQUAL = 1). Finally, the insurer may mimic the efficiency criterion its clientele observes according to economic theory by checking a physician's quality-cost ratio (PHYSEFF $=1$ ).

Insurers also claim that granting access to new therapies and drugs with a lag of 2 years (say) would generate substantial cost savings because the cost of these innovative products goes down as a function of experience in use. This restriction is labeled INNOV $=1$. A hotly debated reform proposal is to reimburse only the generic variant of a medication if available on the Swiss market (MEDIGEN = 1). In a similar vein, the insurer could offer a policy that does not provide reimbursement for 'comfort' drugs designed to alleviate minor health complaints (MEDIMIN =1). There is one aspect of Swiss social health insurance where an extension of coverage is being considered by policy makers. The cost of long-term care services is only covered to the extent that they are strictly medical whereas accommodation in a nursing home must be paid by the elderly person in principle (with social assistance making up for the gap if the pension is insufficient). The proposal is to make individuals aged 50 and more pay a monthly surcharge of CHF 50 (US\$ 38) to finance a LTC supplement $(\mathrm{LTC}=1)$. Finally, small district hospitals are believed not to be cost efficient; therefore, a contract excluding them in favor of larger units at the regional level should achieve some savings $(\mathrm{HOSP}=1)$. The price attribute is the monthly premium that goes along with a contract defined by a combination of these attributes (PREMIUM).

In principle, this design results in 384 possible contract variants. Since this is an excessive number, statistical design theory (Kuhfeld, Tobias \& Garratt, 1994; Hardin \& Sloane, 1993, 1994) was applied to obtain a fractional design that permits estimation of main effects and two-way interaction effects (so-called resolution 5 orthogonal design, see Hedayat, Sloane $\&$ Stufken, et al., 1999). This resulted in 40 alternatives which were randomly assigned to four split samples. Therefore, each participant had to make 10 choices.

The survey proceeded in two steps. In a first telephone contact, people were asked whether they would be willing to take part in the study. Those agreeing to participate received a package containing documentation materials to make sure that all respondents had the same information about the Swiss health care system and knew their current insurance premium. Additionally, each respondent received 11 decision cards for the actual DCE. One card described the status quo; the remaining 10 cards the alternative contracts respondent had to opt for or against. The second step consisted in an appointed telephone interview during the Fall of 2003 and involved 1032 adult residents of Switzerland (excluding the Italian-speaking area of Ticino). Only 28 persons declined to continue to the DCE; the remaining 1004 individuals made 9.8 out of 10 decisions on average. Table 1 displays the composition of the sample, compared to other statistical information on the Swiss resident population where available (see Telser, Vaterlaus, Zweifel and Eugster et al., 2004 for details). On the whole, 
Table 1 Sample and population characteristics

\begin{tabular}{llll}
\hline Socioeconomic characteristic & Sample & Population value & Sources, population values \\
\hline Household size & & & \\
No. members & 2.52 & 2.47 & FSO ICS( 2003) \\
One-person, share & $24.2 \%$ & $32.5 \%$ & FSO ICS ( 2003) \\
Education & & & \\
Compulsory schooling & $8.5 \%$ & $18.4 \%$ & FSO ICS ( 2003) \\
Vocational training & $56.7 \%$ & $56.4 \%$ & FSO ICS ( 2003) \\
University & $11.6 \%$ & $10.8 \%$ & FSO ICS ( 2003) \\
Occupational status & & & \\
Dependent & $49.0 \%$ & $51.0 \%$ & FSO SES( 2003) \\
Independent & $9.7 \%$ & $9.2 \%$ & FSO SES( 2003) \\
Retired & $24.2 \%$ & $20.6 \%$ & FSO SES( 2003) \\
Unemployed & $1.6 \%$ & $3.8 \%$ & \\
Subjective health & & & \\
Excellent & $41 \%$ & & \\
Good & $41 \%$ & & \\
Fair & $12 \%$ & & \\
Medical services used, last 12 months & & & \\
None & $20 \%$ & & \\
Physician & $58 \%$ & & \\
Medication & $45 \%$ & & \\
Hospital & $16 \%$ & & \\
Currently in medical treatment & & & \\
Yes & $31 \%$ & & \\
\hline
\end{tabular}

there does not seem to be serious deviations of sample values from population values that would raise concerns about sample selection bias in estimation.

\section{Econometric results}

\subsection{Specification comprising attributes only}

Although the theoretical example of Section 2 involved coverage for LTC (see Fig. 1 again), this attribute turned out not to be positively valued. It will therefore be left out of the discussion in the following. However, physician choice (the other attribute used in Fig. 1) does constitute a highly valued attribute. This can be gleaned from Table 2 , which shows the results of the regression implementing the specification of Equation (5). All retained attributes have the expected sign and are highly significant.

Conclusion 2: The retained attributes are (with the exception of generic substitution and exclusion of drugs for minor complaints) highly significant determinants of contract choice and hence indirect utility.

From the estimated coefficients shown in Table 2, WTP values (or rather, compensation values, often called willingness to accept) can be calculated. The results for four envisaged regulatory restrictions are displayed in Table 3. To put these estimates in perspective, note that the nationwide average premiums as of 2003 is CHF 270 (US\$208) per month. The standard errors are calculated using the Delta method.

Reading Table 3 horizontally first, one notes that the amounts of compensation asked are consistently highest for consenting to a physician list based exclusively on cost criteria 
Table 2 Random-effects Probit estimation, basic model

\begin{tabular}{|c|c|c|c|c|}
\hline Variable & Coefficient & s.e. & $z$ & $P>|z|$ \\
\hline Physicians selected on cost (PHYSCOST) & $-0.9085349 * * *$ & 0.054660 & -16.62 & 0.000 \\
\hline Physicians selected on quality (PHYSQUAL) & $-0.4691062 * * *$ & 0.052087 & -9.01 & 0.000 \\
\hline Physicians selected on efficiency (PHYSEFF) & $-0.3691041 * * *$ & 0.053688 & -6.87 & 0.000 \\
\hline 2 years for new therapies (INNOV) & $-0.5686612 * * *$ & 0.038207 & -14.88 & 0.000 \\
\hline Generics only (MEDIGEN) & -0.0235289 & 0.048101 & -0.49 & 0.625 \\
\hline No drugs, minor complaints (MEDIMIN) & 0.0569549 & 0.046406 & 1.23 & 0.220 \\
\hline LTC financed by $50+($ LTC) & $-0.219003 * * *$ & 0.038198 & -5.73 & 0.000 \\
\hline Restricted hospital list (HOSP) & $-0.3281199 * * *$ & 0.037891 & -8.66 & 0.000 \\
\hline Health insurance premium (PREM) & $-0.008797 * * *$ & 0.000983 & -8.95 & 0.000 \\
\hline Estimated constant (CONST) & $-0.5124295 * * *$ & 0.079204 & -6.47 & 0.000 \\
\hline$\sigma_{u}$ & 1.052211 & 0.039998 & & \\
\hline$\rho$ & $0.5254248 * * *$ & 0.018957 & & \\
\hline
\end{tabular}

Number of observations $=9850$

$\chi^{2}(9)=573.65 ;$ Prob $>\chi^{2}=0.0000$

Likelihood ratio test of $\rho=0: \chi^{2}(1)=1487.86$; Prob $>=\chi^{2}=0.000$

$* * *$ Coefficient differs from zero at the $0.1 \%$ significance level

(PHYSCOST). The sample average is as high as CHF 103, or some 38\% of the country's average monthly premium. Still, the fact that it does not exceed values that can be offered as premium reduction due to cost savings (Lehmann \& Zweifel, 2004) speaks against the claim (often advanced by medical associations worldwide) that free choice of physician is virtually priceless.

If insurers were to select participating physicians according to quality criteria (PHYSQUAL), compensations required drop by some 50\% on average to CHF 53 (and even 60\% among those aged 25-39, to CHF 33). This does not come as a surprise in a highly insured system, where a low rate of coinsurance (10\%) encourages patients to emphasize quality in their choices. However, the drop in compensation asked is even more marked if the envisaged criteria for selecting physicians are both quality and cost, which amounts to an efficiency criterion (PHYSEFF). This may be astonishing at first sight; however, PHYSEFF implies that the insurer would be applying exactly the same criteria as consumers, the only difference being that insured consumers would use net cost (after insurance) rather than full cost. The health insurer therefore would come close to acting as a perfect agent whose decisions should meet with little resistance by principals.

Delaying access to new therapies and drugs by 2 years (col. 4) would have to be compensated very highly, too. This makes sense because this is a restriction that applies across the board, regardless of the type of therapy (pharmaceutical versus medical) and the setting (ambulatory care versus hospital care). By way of contrast, a drug benefit restricted to generics if available (col. 5) does not even call for a compensation within certain subgroups. There are two likely reasons for this. First, generic drug substitution has been enjoying an increasing degree of acceptance, and second, relatively few original drugs have admitted generic substitutes in Switzerland (their market share being less than 5\%), which means that the corresponding restriction would not be binding very often. When it comes to do without reimbursement of drugs that help against minor complaints (col. 6) the Swiss population even seem to exhibit a small positive WTP for such a restriction. This can be interpreted as an instance of 'warm glow', i.e. the tendency of (at least some) respondents to choose alternatives they believe to be socially acclaimed (Andreoni, 1995). This 'warm glow' effect already disappears, however, with those more likely affected (currently in treatment) exhibiting a positive average amount of compensation asked. 


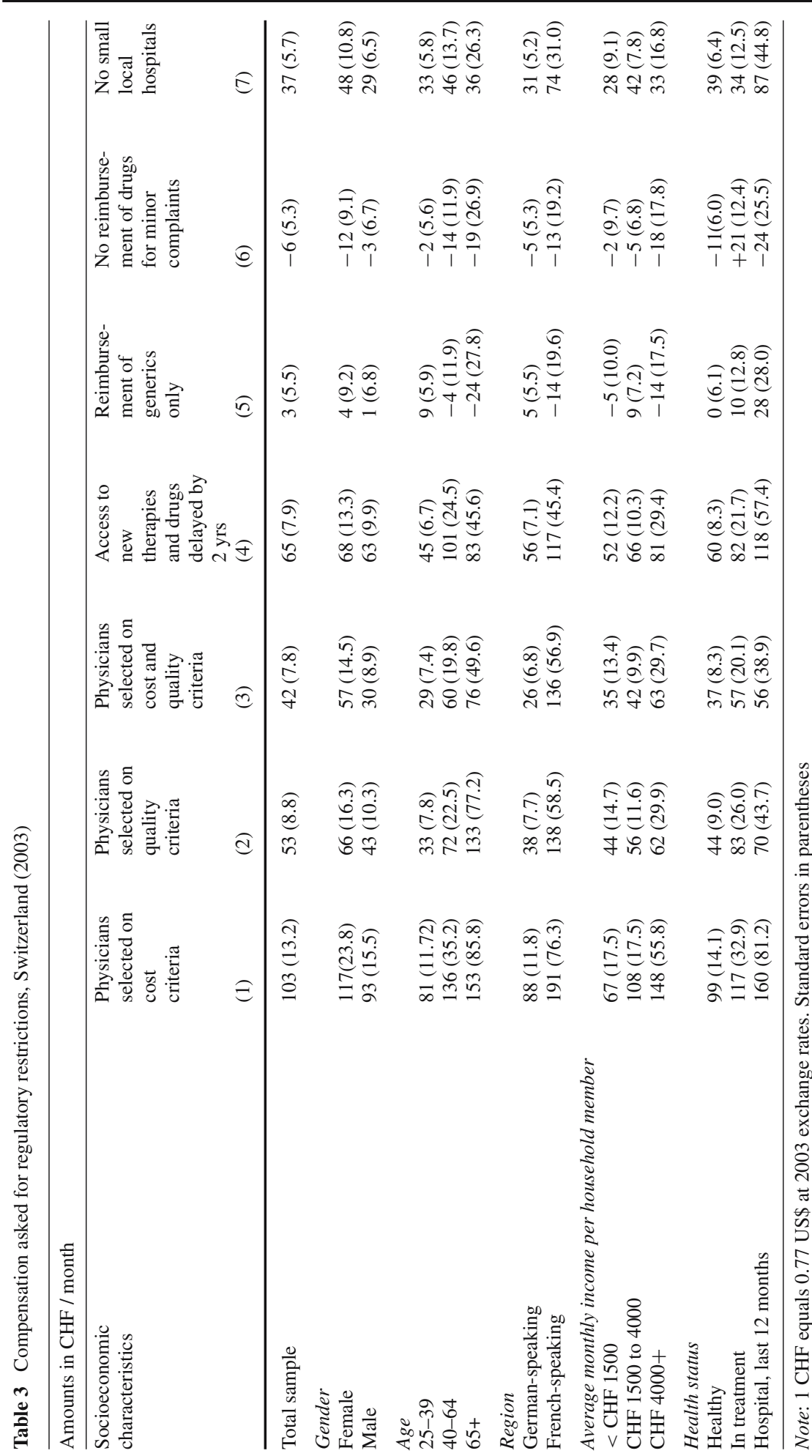


Finally, compensation necessary to make the insured accept having their choice of hospital restricted (by closing inefficient small local units, col. 7) attains values that come close to those of col. 3 (physician list on efficiency criteria). Once more, this has an economic interpretation. On the one hand, an illness calling for hospitalization usually is well beyond a minor complaint, justifying higher values than those of col. 6 of Table 3. Also, substitution of a central for a local hospital quite likely entails a greater sacrifice than substituting a generic for a branded drug (col. 5) in these urgent circumstances. On the other hand, the technology available in the two types of hospital is roughly comparable, whereas lacking access to the newest medical and pharmaceutical technologies for 2 years may entail a marked loss of quality of life in some situations, a fact that is compatible with the values of col. 7 falling somewhat short of those shown in col. 4 of Table 3.

When reading Table 3 vertically, one finds clear evidence of preference heterogeneity. Not surprisingly, regulation restricting physician choice on cost criteria (col. 1 of Table 3 ) would meet with particularly strong resistance among the 65+ age group and those having been in hospital recently. Compensations demanded are 46 and 55\% higher than average, respectively. However, the most salient heterogeneity seems to be a cultural one in that the French-speaking minority exhibits a value that exceeds the average by even $85 \%$. Similar but even more marked differences emerge with regard to the other restrictions of physician choice proposed. For example, when it comes to a selection based on efficiency criteria (col. 3 ), the French-speaking require even more than the triple of the average amount of monthly compensation (CHF 136 vs. 42) for acceptance. Delayed access to new therapies and drugs (col. 4) would be resisted most strongly by the 40-64 years old rather than the oldest. This is less of a surprise than the observation that the compensation necessary to overcome such a regulatory measure would again have to be twice as high for the French-speaking than for the German-speaking population. In relative terms, this cultural divide is at least as marked in the case of accepting generics rather than original drugs and of doing without reimbursement of drugs that help against minor complaints (col. 5 and 6).

Finally, preference heterogeneity shows up importantly again in col. 7 of Table 3 . In spite of a hospital density of 0.8 per 10,000 population, one of the highest figures of the world (OECD, 2003), women are willing to pay the substantial amount of an estimated CHF 48 (US\$ 37) per month to preserve access to local hospitals. This is understandable because of the importance of maternity services to them. Apart from the language divide, those having experienced hospital treatment during the recent past tend to also have higher WTP for continued access to local hospitals.

Conclusion 3: Socioeconomic characteristics are associated with marked differences in required compensations for regulatory restrictions that are interpretable in terms of economic theory. Moreover, regional differences point to considerable preference heterogeneity that likely is culturally determined.

\subsection{Resistance against combined restrictions}

Reforms of the healthcare sector usually proceed in packages which amount to a combination of cutbacks (Cutler, 2002). To the extent that the restrictions considered in the present paper all amount to a loss of freedom of choice, the convexity of the indifference curve can be used to infer that compensation asked for two restrictions combined will exceed the sum of the compensations for each measure separately (see Fig. 1 again).

Table 4 contains evidence to the effect that combining restrictions indeed causes compensation asked to increase in a super-additive manner. For example, the mild restrictions contained in combination No. 1 (physician list based on quality criteria, generic substitution 
Table 4 Compensations asked for combined restrictions, Switzerland (2003)

\begin{tabular}{|c|c|c|c|c|c|}
\hline No. & $\begin{array}{l}\text { Choice of } \\
\text { physician }\end{array}$ & $\begin{array}{l}\text { Access to new } \\
\text { therapies and } \\
\text { drugs }\end{array}$ & Choice of drugs & $\begin{array}{l}\text { Choice of } \\
\text { hospital }\end{array}$ & $\begin{array}{l}\text { Compensation } \\
\text { asked per month }\end{array}$ \\
\hline 1 & $\begin{array}{l}\text { List based on } \\
\text { quality criteria }\end{array}$ & $\begin{array}{l}\text { No change from } \\
\text { status quo }\end{array}$ & $\begin{array}{l}\text { Generics only } \\
\text { (if available) }\end{array}$ & $\begin{array}{l}\text { No change from } \\
\text { status quo }\end{array}$ & CHF 114 \\
\hline 2 & $\begin{array}{l}\text { No change from } \\
\text { status quo }\end{array}$ & Delay of 2 years & $\begin{array}{l}\text { Generics only } \\
\text { (if available) }\end{array}$ & $\begin{array}{l}\text { No change from } \\
\text { status quo }\end{array}$ & CHF 126 \\
\hline 3 & $\begin{array}{l}\text { List based on cost } \\
\text { and quality criteria }\end{array}$ & $\begin{array}{l}\text { No change from } \\
\text { status quo }\end{array}$ & $\begin{array}{l}\text { No reimbursement in } \\
\text { case of minor complaint }\end{array}$ & No local hospitals & CHF 131 \\
\hline 4 & $\begin{array}{l}\text { List based on cost } \\
\text { criteria }\end{array}$ & Delay of 2 years & $\begin{array}{l}\text { No reimbursement in } \\
\text { case of minor complaint }\end{array}$ & No local hospitals & CHF 257 \\
\hline
\end{tabular}

where possible, no change from status quo otherwise) calls forth a compensation of CHF 114 per month. This substantially exceeds the sum of the respective amounts shown in cols. 2 and 5 of Table $3(56=53+3)$. Superadditivity is however less marked when three restrictions are combined, as in the particularly harsh combination No. 4 of Table 4 (physician list based on cost criteria, delayed access to innovation, no reimbursement of drugs for the treatment of minor complaints, no local hospitals). This regulatory package would have to be compensated with CHF 257, whereas the sum of compensations (taken from cols. 1, 4, 6, and 7 of Table 3 ) amounts to CHF 199(=103+65-6+37). However, combined restrictions do require superadditive compensation without exception. This is importantly due to the fact that when combining attributes to a product, the constant of Equation (6) enters the calculation. A changing constant can impart proximate convexity to the indifference curve (which is locally linearized in the Probit estimation of Table 2). In sum, the estimates shown in Table 4 suggest that piecemeal regulation may meet with less resistance than entire packages, at least in the case of health care.

\subsection{Dispersion of WTP estimates}

An important piece of evidence regarding preference heterogeneity is provided by an analysis of the distribution of WTP estimates. As shown in Table 5, the lowest quartiles and deciles are at a considerable distance from the overall mean value of WTP. For example, while on average the compensation demanded for voluntary accepting a physician list based on cost criteria only (PHYSCOST) amounts to CHF 103, the lowest quartile is at CHF 76 and lowest decile even at CHF 59 or some $22 \%$ of average premium, a clear sign of preference heterogeneity. Independent research suggests that the short to medium term savings

Table 5 Compensation asked for regulatory restrictions: means, lowest quartiles, lowest deciles (CHF/month)

\begin{tabular}{llll}
\hline Restrictions proposed & Mean value & Lowest quartile & Lowest decile \\
\hline Physicians selected on cost (PHYSCOST) & 103 & 76 & 59 \\
Physicians selected on quality (PHYSQUAL) & 53 & 26 & 17 \\
Physicians selected on efficiency (PHYSEFF) & 42 & 18 & 10 \\
2 years for new therapies (INNOV) & 65 & 43 & 35 \\
Generics only (MEDIGEN) & 3 & -12 & -36 \\
No drugs, minor complaints (MEDIMIN) & -6 & -23 & -41 \\
Restricted hospital list (HOSP) & 37 & 29 & 15 \\
\hline
\end{tabular}


associated with such a restriction can be as high as $50 \%$, while federal regulation permits insurers to lower premiums only by $20 \%$ during the first 5 years following the launch of a Managed-Care alternative (Lehmann \& Zweifel, 2004). Therefore, the market share of this HMO-type contract should be somewhat less than 10\%; it in fact hovers around 6 percent (Swiss Federal Agency for Social Insurance, 2003, item KV 5.2).

Preference heterogeneity is even more marked with regard to a physician list based on efficiency criteria (PHYSEFF). Here, the average WTP value is 42 , while it falls to a mere CHF 10 (roughly $25 \%$ of the mean) for the lowest decile of the distribution.

Conclusion 4: Amounts of compensation asked tend to increase progressively when restrictions are combined, as predicted by theory. Also, a high degree of dispersion in the distribution of estimated WTP values points to marked preference heterogeneity.

\section{Conclusions}

Regulation tends to burden both producers and consumers with efficiency losses. Nevertheless, it may be justified if it helps to avoid or reduce externalities. In this case, observing market behavior for inferring efficiency losses constitutes an imperfect guide for policy. In the context of health care, the externality to be considered is moral hazard, which can be controlled by imposing restrictions on the choice of health care providers and therapies covered by insurance. Therefore, it may be inappropriate to use observed behavior of patients and healthcare providers for designing reforms. When such restrictions are in the planning stage, behavior under regulation cannot be observed. In this situation, the use of experiments simulating market behavior can provide valuable guidance.

The discrete choice experiments reported here have the advantage of realism (Conclusion 1). They are realistic because respondents had to decide between a fixed status quo and a series of alternatives that simultaneously change in all relevant product attributes, not only price (as in contingent valuation). They are realistic also because under the pressure of competition, insurers who successfully control moral hazard (thus achieving a cost advantage) will have to offer lower premiums. In the case of Switzerland, this scenario is credible because contracts already exist that offer a premium reduction in return for certain restrictions of the managed-care type (Lehmann \& Zweifel, 2004). It may be this realism that contributed to a very low rate of refusals in the experiment and clear evidence in favor of trade-offs between non-price and price attributes of the proposed alternatives.

The great majority of the regulatory restrictions considered do impart utility losses to respondents (Conclusion 2). Compensations required to make respondents voluntarily accept these restriction can be shown to importantly differ between groups. The highest compensation asked pertains to restrictions of physician choice; however these amounts are finite, and at least for some segments of the insured population, the achievable cost savings suffice to finance them. In particular, this refutes the claim often advanced by the medical profession that free physician choice is virtually priceless. Indeed, immediate access to new therapies and drugs seem to command a comparable value, at least in the case of the Swiss population.

To the extent that the aged may be exposed to increased health risk, against which they want to buy health insurance coverage, microeconomic theory predicts their compensation to be higher than average (Arrow, 1971, ch. 3). This prediction is borne out in all the variants of physician lists considered here. While no economic predictions can be made regarding the ceteris paribus-difference between the German-speaking and French-speaking regions, the 
fact that compensations asked are up to five times higher in the French-speaking region point to a great deal of preference heterogeneity. Turning to income, the general pattern conforms to economic predictions in that higher income is associated with higher compensation asked for a good such as freedom of choice, which must be particularly valuable when financial constraints are not so binding. Not surprisingly, those having undergone either ambulatory or hospital treatment in the recent past put a particularly high value on unrestricted choice of physician (Conclusion 3). Finally, the marked dispersion characterizing the distribution of estimated WTP values, with the lowest decile $50 \%$ or even $25 \%$ of the mean, also suggests marked heterogeneity of preferences in the Swiss population concerning the provision of health care (Conclusion 4).

This preference heterogeneity militates against the introduction of regulation imposing uniform Managed-Care type policies on health insurers and hence consumers. Rather, insurers need the freedom to develop policies that match the preferences of subsets of the population, to whom they are able to offer a premium reduction corresponding to the amount of compensation asked for accepting the pertinent restrictions on the provision of health care.

Acknowledgements The authors gratefully acknowledge helpful suggestions and criticisms by an anonymous referee.

\section{References}

Andreoni, J. (1995). Warm-glow vs. cold-prickle: the effects of positive and negative framing on cooperation in experiments. Quarterly Journal of Economics, 110(1), 1-21.

Arrow, K. J. (1971). Essay in the theory of risk bearing. Amsterdam: North Holland.

Ben-Akiva, M. E., \& Lerman, S. R. (1985). Discrete choice analysis. Chap. 3, Cambridge, London: MIT Press.

Cattin, P., \& Wittink, D. R. (1982). Commercial use of conjoint analysis: a survey. Journal of Marketing, 46, 44-53.

Cutler, D. M. (2002). Equality, efficiency, and market fundamental: the dynamics of international medical-care reform. Journal of Economic Literature, XL (3), 881-906.

Gustafson, A., Herrmann, A., \& Huber, F. (2000). Conjoint analysis as an instrument of market research practice. In, A. Gustafsson, A. Herrmann, \& F. Huber (Eds.) Conjoint measurement: methods and applications. (pp. 5-46) Heidelberg and New York: Springer.

Gyrd-Hansen, D., \& Slothuus, U. (2002). The citizen's preferences for financing public health care: a danish survey. International Journal of Health Care Finance \& Economics, 2(1), 25-36.

Hanemann, W. M. (1983). Marginal welfare measures for discrete choice models. Economics Letters 13, $129-136$.

Hardin, R. H., \& Sloane, N. J. A. (1993). A new approach to the construction of optimal designs. Journal of Statistical Planning and Inference, 37, 229-369.

Hardin, R. H., \& Sloane, N. J. A. (1994). Operating manual for gosset: a general purpose program for constructing experimental designs, 2nd edition. http://www.research.att.com/ njas/gosset/.

Hedayat, A. S., Sloane, N. J. A., \& Stufken, J. (1999). Orthogonal arrays. theory and applications. New York, Berlin, Heidelberg: Springer.

Interstudy (2003). HMO industry report. St. Paul, MA: Interstudy.

Johnson, F. R., \& Desvousges, W. H. (1997). Estimating stated preferences with rated-pair data: environmental, health, and employment effects of energy programs. Journal of Environmental Economics and Management, 34, 79-99.

Kuhfeld, W. F., Tobias, R. D., \& Garratt, M. (1994). Efficient experimental design with marketing research applications. Journal of Marketing Research, 31, 545-557.

Lancaster, K. (1966). A new approach to consumer theory. Journal of Political Economy, 74, 132-157.

Lehmann, Hj., \& Zweifel, P. (2004). Innovation and risk selection in deregulated social health insurance. Journal of Health Economics, 23, 997-1012.

Louviere, J. J., Hensher, D. A., \& Swait, J. D. (2000). Stated choice methods-analysis and application. Cambridge: Cambridge University Press.

McFadden, D. (1974). Conditional logit analysis of qualitative choice behavior. In P. Zarembka (Ed.), Frontiers in econometrics. (pp. 105-142) New York: Academic Press. 
Mitchell, R. C., \& Carson, R. T. (1989). Using survey to value public goods, the contingent valuation method. Washington DC: Resources for the Future.

OECD (2003). OECD Health Data, Paris.

Ryan, M., \& Hughes, J. (1997). Using conjoint analysis to assess women's preference for miscarriage management. Health Economics, 7, 373-378.

Swiss Federal Agency for Social Insurance (Bundesamt für Sozialversicherung) (2003). Schweizerische Sozialversicherungsstatistik (2003) (Statistics of Swiss Social Insurance). Bern: EDMZ.

Telser, H., Vaterlaus, S., Zweifel, P., \& Eugster, P. (2004). Was leistet unser Gesundheitswesen? (What performance our healthcare system?). Zurich: Rüegger.

Telser, H., \& Zweifel, P. (2002). Measuring willingness-to-pay for risk reduction: an application of conjoint analysis. Health Economics, 11, 129-139.

Zweifel, P., \& Breyer, F. (1997). Health economics. New York: Oxford University Press. 